\title{
Correction to: Hyperpyrexia and high fever as a predictor for serious bacterial infection (SBI) in children-a systematic review
}

\author{
Noa Rosenfeld-Yehoshua ${ }^{1,2} \cdot$ Shiri Barkan ${ }^{2,3} \cdot$ Ibrahim Abu-Kishk $^{1,2} \cdot$ Meirav Booch $^{4} \cdot$ Ruth Suhami $^{5} \cdot$ Eran Kozer $^{2,3}$
}

Published online: 21 November 2019

(C) Springer-Verlag GmbH Germany, part of Springer Nature 2019

\section{Correction to: European Journal of Pediatrics (2018) 177:337-344} https://doi.org/10.1007//s00431-018-3098-x

It has been identified that the data listed within the above article was incorrectly presented. This is now presented correctly in this article.

In section 'Conclusion:' under Abstract the article reads:

"Conclusion: Young infants with temperature higher than $400{ }^{\circ} \mathrm{C}$ are at increased risk for SBI. Risk of SBI in older children with temperature $>\mathbf{4 0 0 C}$ is minimal."

The sentence should read:

"Conclusion: Young infants with temperature higher than $40{ }^{\circ} \mathbf{C}$ are at increased risk for SBI. Risk of SBI in older children with temperature $>\mathbf{4 0}{ }^{\circ} \mathrm{C}$ is minimal."

No further corrections have been made.

The online version of the original article can be found at https://oi.org/ 10.1007/s00431-018-3098-x

Noa Rosenfeld-Yehoshua

Rosenfeldnoa@gmail.com

Shiri Barkan

drbarkans@gmail.com

Ibrahim Abu-Kishk

ibrahima@asaf.health.gov.il

Meirav Booch

mairav@asaf.health.gov.il

Ruth Suhami

rutisu@tauex.tau.ac.il
Eran Kozer

erankozer@hotmail.com

1 Pediatric Intensive Care Unit, Assaf Harofeh Medical Center, Zerifin, Israel

2 Sackler Faculty of Medicine, Tel Aviv University, Tel Aviv, Israel

3 Pediatric Emergency Unit, Assaf Harofeh Medical Center, Zerifin, Israel

4 Medical Library, Assaf Harofeh Medical Center, Zerifin, Israel

5 Gitter-Smolarz Life Science \& Medicine Library, Tel Aviv University, Tel Aviv, Israel 